\title{
MIXED CONVECTION IN A SINGLE-WALLED CARBON NANOTUBE-WATER NANOFLUID FILLED PARTIALLY HEATED TRIANGULAR LID-DRIVEN CAVITY HAVING AN ELASTIC BOTTOM WALL
}

\author{
Fatih Selimefendigil ${ }^{1, *}$, Hakan F. Öztop²
}

\begin{abstract}
In this study, mixed convection of nanofluid filled triangular cavity with a partial heater and having an elastic bottom wall is analyzed with finite element method. Left vertical wall is partially heated while the inclined wall is kept at constant lower temperature. The bottom wall is flexible and inclined wall is moving at constant speed. Influences of Richardson number, elastic modulus of flexible wall, solid nanoparticle volume fraction on the convective heat transfer characteristics are analyzed. It was observed that, lower values of Richardson number, elastic modulus of the flexible wall and higher values of nano-particle volume fraction resulted in higher local and average heat transfer enhancements. Average heat transfer enhanced significantly when solid particle volume fraction of nanoparticle was increased. Enhancements up to $121 \%$ were obtained at solid volume fraction of 0.04 as compared to pure water at Richardson number of 1 . Effects of elastic modulus of the bottom wall were found to be marginal and at $\mathrm{Ri}=1$, enhancements up to $2 \%$ were achieved by using a more flexible wall.
\end{abstract}

\section{Keywords: Carbon Nanotube, Nanofluid, Flexible Wall, Mixed Convection, Simulation}

\section{INTRODUCTION}

Mixed convective heat transfer due to a moving surface plays an important role in different thermal engineering applications such as in nuclear reactors, food processing, chemical processes, cooling of electronic devices and many others. Triangular shaped geometries are important for electronic devices, building roof applications and solar power applications. In order to control the convective heat transfer characteristics in a mixed convection configuration, many attempts can be made. The mixed convection in cavities can be affected by using flexible walls [1-4]. A numerical study for the mixed convective heat transfer in a nanofluid filled square cavity having flexible side walls and with internal heat generation was performed in Ref. [3]. They showed that the Nusselt number reduces as the elastic modulus of the flexible wall increases. Mixed convection a lid driven cavity with a flexible bottom wall was investigated in ref. [4] and it was observed that profound enhancement in the heat transfer with flexible wall achieved when compared with flat wall configuration.

Recently, a new type of heat transfer fluid called nanofluid is widely used in thermal engineering applications. Nano-sized metallic or non-metallic particles are added to the base fluid such as water and ethyleneglycol to enhance the heart transfer characteristics. Many studies related to application of nanofluid in heat transfer area can be found in different references [5-7]. As compared to other particles carbon nanotubes (CNT) have significantly higher thermal conductivities. Recently, profound enhancements in the heat transfer coefficients were reported by using carbon nanotubes [8-11]. It was shown that, better thermal performance enhancements at relatively lower pressure can be obtained with CNT when compared to other nanoparticles. It was also shown that single wall carbon nanotubes have higher heat transfer rate as compared to multiple wall carbon nanotubes. In this study we considered the mixed convection of carbon nanotube-water nanofluid filled triangular cavity having a flexible wall

This paper was recommended for publication in revised form by Regional Editor Tolga Taner

${ }^{1}$ Department of Mechanical Engineering, Manisa Celal Bayar University, Manisa, Turkey

${ }^{2}$ Department of Mechanical Engineering, Technology Faculty, Fırat University, Elazığ, Turkey

${ }^{*}$ E-mail address: fatih.selimefendigil@cbu.edu.tr

Orcid ids: https://orcid.org/0000-0002-5453-2091, https://orcid.org/0000-0002-2161-0639

Manuscript Received 26.01.2018, Accepted 08.04.2018 
for various pertinent parameters of the system. This configuration can be encountered in a variety of thermal engineering applications such as in electronic cooling, chemical processes, food industry and many others.

The results of the present study can be used for thermal modelling and optimization studies in the mentioned applications with similar geometries.

\section{METHODOLOGY}

\section{Numerical Modelling}

A schematic view of the computational model is given in Figure 1.

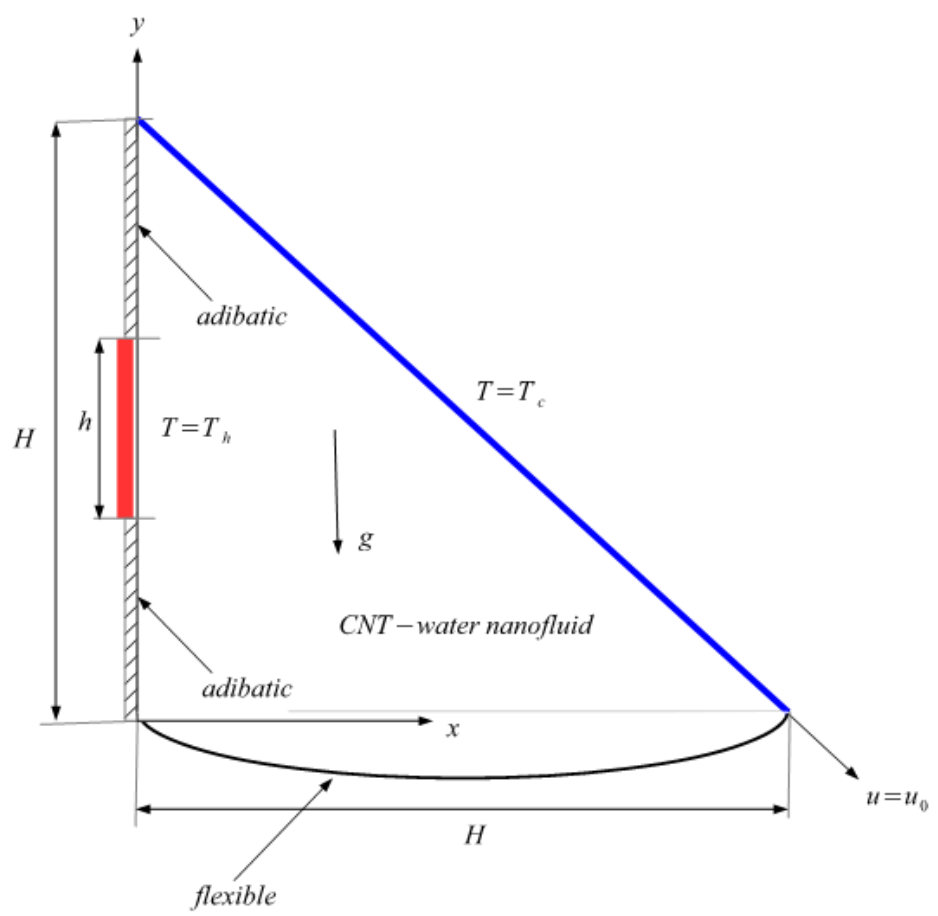

Figure 1. Schematic view of the computational study

A triangular cavity with a bottom elastic wall is considered. It is partly heated from the left vertical side $\left(T=T_{h}\right)$ while the inclined wall is kept at constant cold temperature of $T_{c}\left(T_{h}>T_{c}\right)$. The inclined wall of the cavity is moving with velocity $\mathrm{u}_{0}$ in the tangential direction. The cavity is filled with single walled carbon nanotube (SWCNT)-water nanofluid with various solid volume fractions of nanoparticles. The bottom wall is made flexible with elastic modulus of E. Gravity acts in the negative y direction. Boussinesq approximation was used to model the density variation while thermal radiation and viscous dissipation effects are neglected. Navier-Stokes and energy equations with effective thermo-physical properties is written as [4]:

$$
\begin{gathered}
\nabla \cdot u=0 \\
\rho_{n f}\left(u-u_{g}\right) \cdot \nabla u=\nabla \cdot \sigma_{n f}+\rho_{n f} f_{f}^{b} \\
u \nabla T=\alpha_{n f} \nabla^{2} T
\end{gathered}
$$

Solid domain equation for the fluid-structure interaction model is given as: 
Journal of Thermal Engineering, Research Article, Vol. 6, No. 6, Special Issue 12, pp. 379-387,

December, 2020

$$
\rho_{s} a_{s}=\nabla \cdot \sigma_{s}+f_{s}^{b}
$$

The relevant non-dimensional quantities are:

$$
\mathrm{Gr}=\frac{g \beta\left(T_{h}-T_{c}\right) H^{3}}{v^{2}}, \quad \operatorname{Pr}=\frac{v}{\alpha}, \quad \mathrm{Re}=\frac{u_{0} H}{v}, \quad \mathrm{Ra}=\mathrm{GrPr}, \quad \mathrm{Ri}=\frac{\mathrm{Gr}}{\mathrm{Re}^{2}}
$$

The boundary conditions are defined as:

For the partial heater, $u=v=0, \quad T=T_{h}$

For the adiabatic walls, $u=v=0, \frac{\partial T}{\partial n}=0$

For the inclined wall, $u=u_{0} \sin (\gamma), \quad v=u_{0} \cos (\gamma), \quad T=T_{h}$

At the fluid-structure interface, $\sigma_{f}=\sigma_{s}, d_{f}=d_{s}$

Local and average heat transfer are calculated as:

$$
N u_{y}=-\frac{k_{n f}}{k_{f}}\left(\frac{\partial \theta}{\partial X}\right), \quad N u_{m}=\frac{1}{h} \int_{y}^{y+h} N u_{y} d y
$$

\section{Nanofluid Effective Properties}

Thermophysical properties of water and single walled carbon nanotube (SWCNT) are given in Table 1 [9]. Density and specific heat of the nanofluid are given in terms of base fluid, carbon nanotube properties and solid volume fraction as [8]:

$$
\begin{aligned}
\rho_{n f} & =(1-\phi) \rho_{f}+\phi \rho_{C N T} \\
\left(\rho C_{p}\right)_{n f} & =(1-\phi)\left(\rho C_{p}\right)_{f}+\phi\left(\rho C_{p}\right)_{C N T}
\end{aligned}
$$

Brinkman model was used for the dynamic viscosity of the nanofluid [12]:

$$
\mu_{n f}=\frac{\mu_{f}}{(1-\phi)^{2.5}}
$$

Thermal conductivity for water-CNT nanofluid takes into account the space distribution of the carbon nanotubes on the thermal conductivity and it is given as [8]:

$$
\frac{k_{n f}}{k_{f}}=\frac{(1-\varphi)+2 \varphi \frac{k_{C N T}}{k_{C N T}-k_{f}} \ln \frac{k_{C N T}+k_{f}}{2 k_{f}}}{(1-\varphi)+2 \varphi \frac{k_{f}}{k_{C N T}-k_{f}} \ln \frac{k_{C N T}+k_{f}}{2 k_{f}}}
$$

Table 1. Thermophysical properties of base fluid and single walled CNT

\begin{tabular}{|c|c|c|}
\hline Property & Water & CNT \\
\hline $\mathbf{\rho ~ ( k g ~ / \mathbf { m } ^ { \mathbf { 3 } } )}$ & 997.1 & 2600 \\
\hline $\mathbf{C p}(\mathbf{J} / \mathbf{k g ~ K})$ & 4179 & 425 \\
\hline $\mathbf{k}(\mathbf{W} / \mathbf{m} \mathbf{K})$ & 0.61 & 6600 \\
\hline
\end{tabular}




\section{Solution Method}

Governing equations along with the boundary conditions are solved with Galerkin weighted residual finite element method. Flow variables are approximated by using the interpolation functions in the finite elements of the computational domain as:

$$
\begin{gathered}
u=\sum_{i=1}^{N^{u}} \Psi_{k}^{u, V} U_{k}, \quad V=\sum_{i=1}^{N^{v}} \Psi_{k}{ }^{u, V} V_{k} \\
p=\sum_{i=1}^{N^{p}} \Psi_{k}^{p} P_{k}, \quad T=\sum_{i=1}^{N^{T}} \Psi_{k}^{T} T_{k}
\end{gathered}
$$

where $\Psi_{k}^{u, v, P, T}$ represents the shape functions for velocities, pressure and temperature. $U, V$ and $T$ denote the values of the respective variables at the nodes of the element. Lagrange finite elements were used to approximate the flow variables. When the approximated field variables are inserted into the governing equations, it will result in residual $\boldsymbol{R}$ and the weighted average of this residual will be forced to be zero over the computational domain as:

$$
\int_{\Omega} W_{k} R d V=0
$$

where $\boldsymbol{w}_{\boldsymbol{k}}$ denotes the weight function. In the Galerkin method, the weight function is chosen from the same set of functions as of the trial functions. The resulting system of nonlinear ordinary differential equations were solved by using Newton-Raphson method. The details for finite element modelling in convective heat transfer can be found in [13-14]. Grid independence of the solution is assured by various numerical experiments with different number of elements. The present code was validated by using the numerical results in ref. [5]. Comparison of v-velocity and local Nusselt number in a cavity at Rayleigh number of $10^{5}$ is shown in Figure 2.

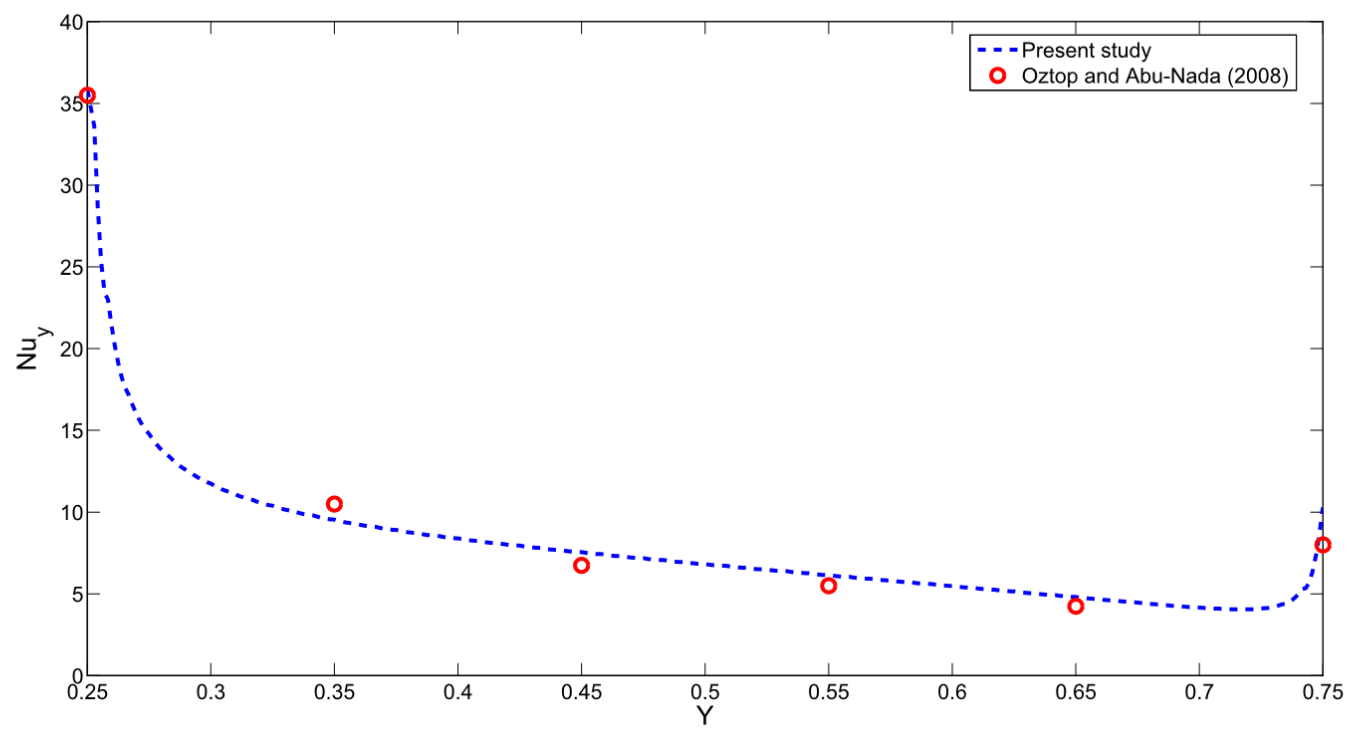

Figure 2. Code validation study with ref. [5] 


\section{RESULTS AND DISCUSSIONS}

Effects of variation of Richardson number on the distribution of streamlines and isotherms are shown in Figure 3. A lower value Richardson number represents a higher value of lid velocity of the inclined wall since Grashof number is fixed. As the value of Ri enhances, the bottom wall flexibility exhibits more and there are slight changes in the form and center location of the single recirculating vortex within the cavity. Isotherms are more clustered near the bottom part of the partial heater indicating higher heat transfer process in those locations. As the value of Ri enhances, thermal gradients become less stepper along the heater and conduction mode of heat transfer becomes effective at the highest value of Richardson number. Local Nusselt number decrease for higher values of Ri number and attains lower values in the vicinity of the mid of the partial heater (Figure 4).

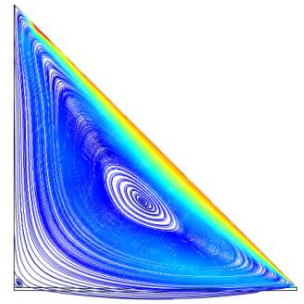

a) $\mathrm{Ri}=0.25$

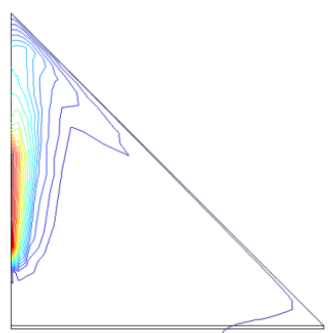

a) $\mathrm{Ri}=0.25$

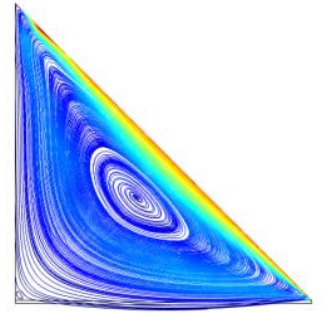

b) $\mathrm{Ri}=1$

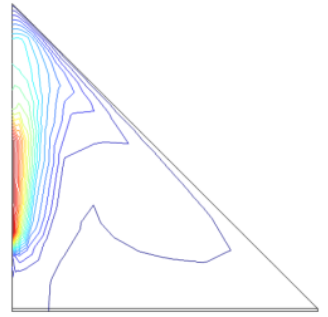

b) $\mathrm{Ri}=1$

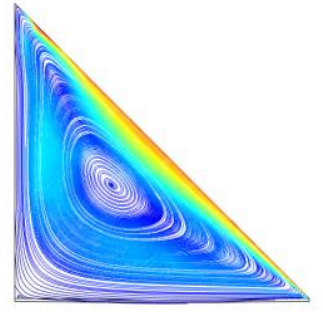

c) $\mathrm{Ri}=25$

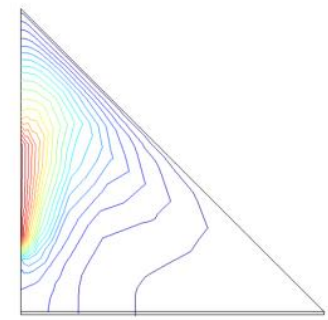

c) $\mathrm{Ri}=25$

Figure 3. Distribution of streamlines and isotherms for different Richardson numbers $\left(E=10^{4}, \varphi=0.04\right)$

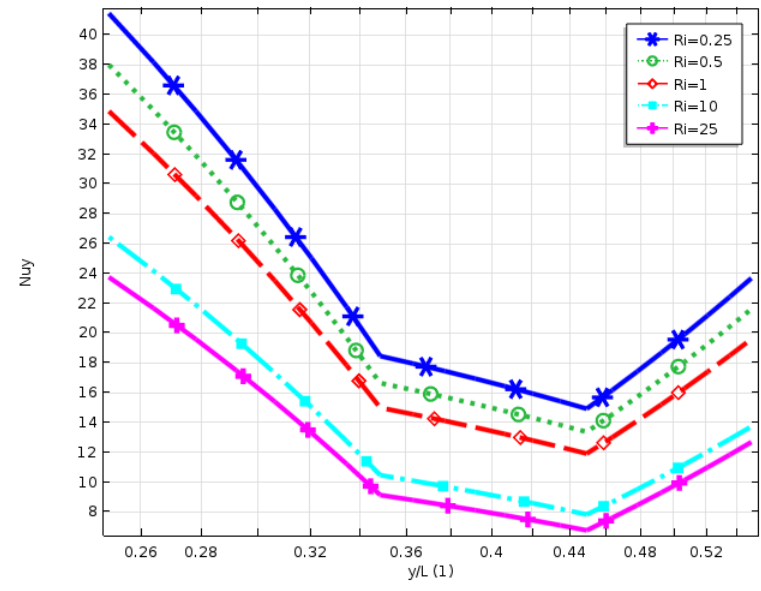

Figure 4. Local Nusselt number distributions for different Ri numbers $\left(E=10^{4}, \varphi=0.04\right)$

Effects of flexible wall on the distribution of streamlines and isotherms are shown in Figure 5 for two different elastic moduli of the bottom wall. For the lower value of elastic modulus, some more additional space for the movement of the fluid is provided and this results in slight change of vortex center location and its size within the cavity. Local Nusselt number changes in the location closer to the top and bottom part of the heater especially for the lower value of Ri number when lid-velocity becomes higher (Figure 6). There is negligible change in the heat transfer rate when Ri number becomes higher. Table 2 shows the variation of average Nusselt number along the 
heater for different Richardson number and elastic moduli of the flexible wall. $47.9 \%$ reduction in the average heat transfer rate is obtained when $\mathrm{Ri}$ is increased from 0.25 to $\mathrm{Ri}=25$ for a rigid wall case. There is very slight change of average Nusselt number when the bottom wall is made flexible and this is more effective for a lower value of Richardson number where the velocity of the moving wall is higher. As compared to other studies related to convection in flexible walled cavities, the location of the flexible part become important for the heat transfer enhancement. In the study in ref. [15] where mixed convection in a 3D cavity with flexible surfaces was analysed, the average heat transfer heat transfer was found to enhance by about $9.8 \%$ when elastic modulus of the flexible wall was increased. In another study in ref. [15], only $5.86 \%$ of the average Nusselt number was found to increase when a flexible wall was used instead of a rigid one but in the presence of magnetic field effects.

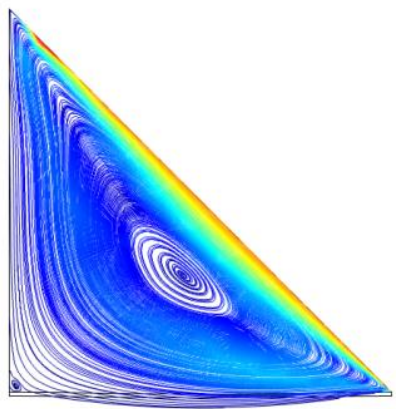

a) $\mathrm{E}=10^{4}$

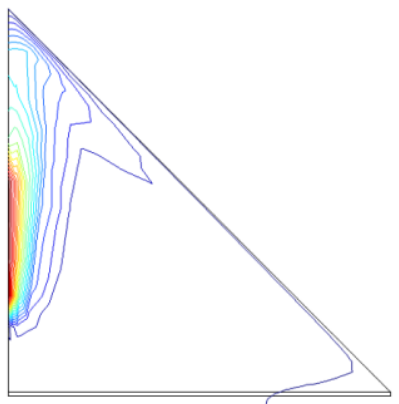

c) $\mathrm{E}=10^{4}$

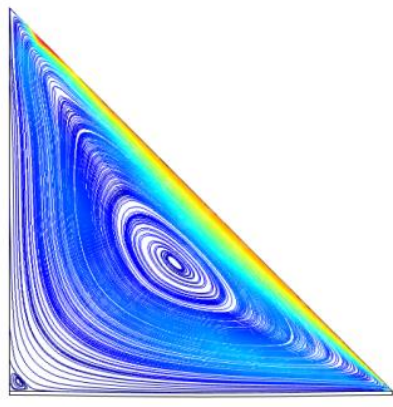

b) $\mathrm{E}=10^{6}$

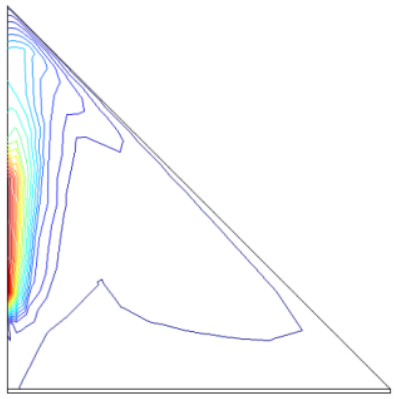

d) $\mathrm{E}=10^{6}$

Figure 5. Distribution of streamlines and isotherms for two elastic moduli values $(\mathrm{Ri}=0.25, \varphi=0.04)$

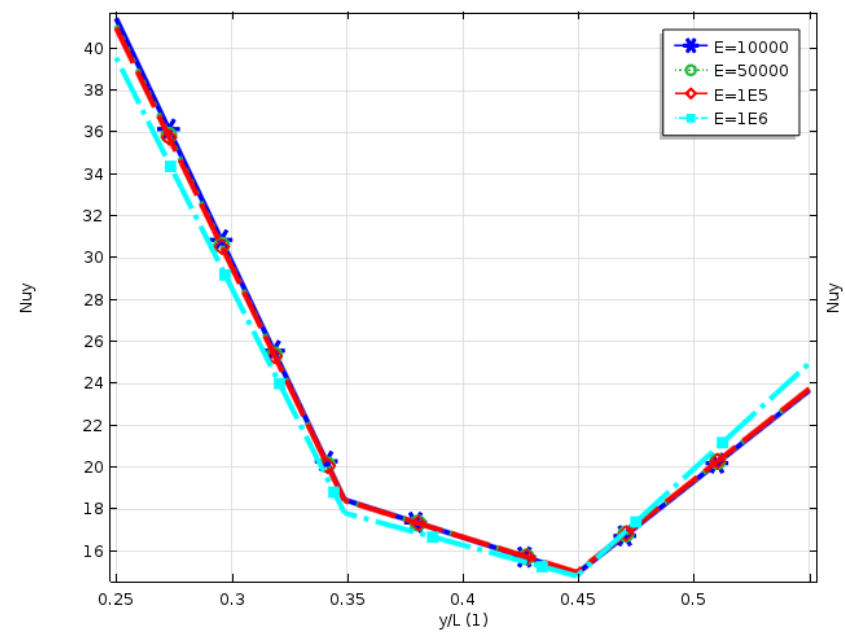

a) $\mathrm{Ri}=\mathbf{0 . 2 5}$

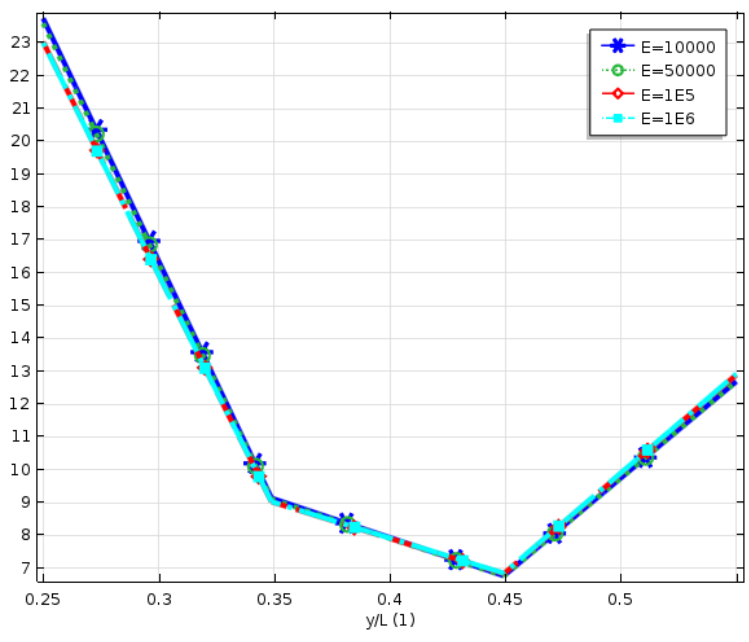

b) $\mathbf{R i}=\mathbf{2 5}$

Figure 6. Variation of local Nusselt number for different elastic moduli at two Richardson number values $(\varphi=0.04)$ 
Journal of Thermal Engineering, Research Article, Vol. 6, No. 6, Special Issue 12, pp. 379-387,

December, 2020

Table 2. Average Nusselt number for various Richardson number and elastic moduli $(\varphi=0.04)$

\begin{tabular}{|c|c|c|}
\hline $\mathbf{R i}$ & $\mathbf{E}$ & $\begin{array}{c}\text { Average Nusselt } \\
\text { number }\end{array}$ \\
\hline 0.25 & $10^{4}$ & 21.938 \\
\hline 0.25 & $5 \times 10^{4}$ & 21.898 \\
\hline 0.25 & $10^{5}$ & 21.885 \\
\hline 0.25 & $5 \times 10^{5}$ & 21.840 \\
\hline 0.25 & $10^{6}$ & 21.597 \\
\hline 0.50 & $10^{4}$ & 19.899 \\
\hline 0.50 & $5 \times 10^{4}$ & 19.848 \\
\hline 0.50 & $10^{5}$ & 19.832 \\
\hline 0.50 & $5 \times 10^{5}$ & 19.790 \\
\hline 0.50 & $10^{6}$ & 19.554 \\
\hline 1 & $10^{4}$ & 18.012 \\
\hline 1 & $5 \times 10^{4}$ & 17.956 \\
\hline 1 & $10^{5}$ & 17.939 \\
\hline 1 & $5 \times 10^{5}$ & 17.619 \\
\hline 1 & $10^{6}$ & 17.638 \\
\hline 10 & $10^{4}$ & 12.767 \\
\hline 10 & $5 \times 10^{4}$ & 12.720 \\
\hline 10 & $10^{5}$ & 12.705 \\
\hline 10 & $5 \times 10^{5}$ & 12.578 \\
\hline 10 & $10^{6}$ & 12.580 \\
\hline 25 & $10^{4}$ & 11.346 \\
\hline 25 & $5 \times 10^{4}$ & 11.307 \\
\hline 25 & $10^{5}$ & 11.245 \\
\hline 25 & $5 \times 10^{5}$ & 11.251 \\
\hline 25 & $10^{6}$ & 11.252 \\
\hline
\end{tabular}

Adding nanoparticles to the base fluid results in higher thermal conductivity enhancements. As compared to other particles carbo-nanotubes have very higher thermal conductivity and significant enhancements of thermal conductivity is achieved even for very small amount of particle inclusion top the base fluid. Figure 7 shows the variation of local Nusselt number for various solid particle volume fractions. Local heat transfer enhancement is higher for the locations where heat transfer is higher. Average heat transfer enhances by about $121.66 \%$ and $118.60 \%$ for the nanofluid at the highest particle volume fraction as compared to pure water for Richardson number of 0.25 and 25, respectively as it is shown in Table 3.

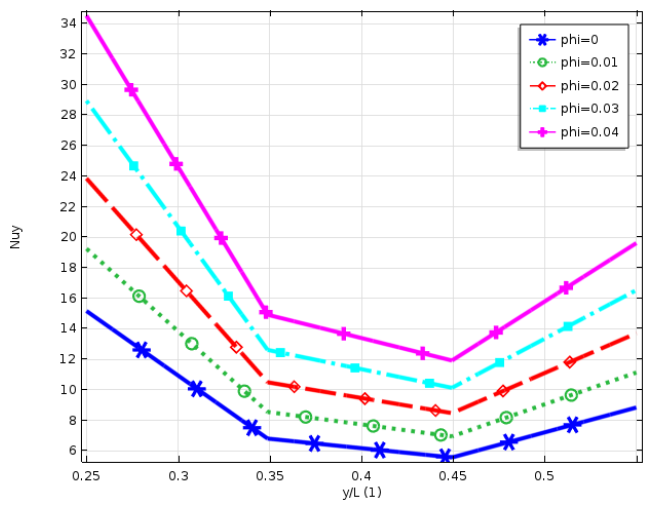

Figure 7. Local Nusselt number variation for various values of nanoparticle solid volume fraction $\left(\mathrm{Ri}=1, \mathrm{E}=10^{5}\right)$ 
Journal of Thermal Engineering, Research Article, Vol. 6, No. 6, Special Issue 12, pp. 379-387, December, 2020

Table 3. Effects of solid particle volume fraction on the heat transfer enhancement for various Richardson numbers $\left(\mathrm{E}=10^{4}\right)$

\begin{tabular}{|c|c|c|}
\hline $\mathbf{R i}$ & $\varphi$ & $\begin{array}{c}\text { Average Nusselt } \\
\text { number }\end{array}$ \\
\hline 0.25 & 0 & 9.8971 \\
\hline 0.25 & 0.01 & 12.469 \\
\hline 0.25 & 0.02 & 15.344 \\
\hline 0.25 & 0.03 & 18.499 \\
\hline 0.25 & 0.04 & 21.938 \\
\hline 1 & 0 & 8.1449 \\
\hline 1 & 0.01 & 10.253 \\
\hline 1 & 0.02 & 12.610 \\
\hline 1 & 0.03 & 15.197 \\
\hline 1 & 0.04 & 18.012 \\
\hline 25 & 0 & 5.1902 \\
\hline 25 & 0.01 & 6.4959 \\
\hline 25 & 0.02 & 7.9576 \\
\hline 25 & 0.03 & 9.5711 \\
\hline 25 & 0.04 & 11.346 \\
\hline
\end{tabular}

\section{CONCLUSIONS}

Mixed convection of single walled carbon nanotube-water nanofluid filled triangular cavity with a flexible bottom wall and inclined moving wall was performed. It was observed that local and average heat transfer enhances for lower values of Richardson number and nanoparticle volume fraction. The effect of wall elasticity on the heat transfer is effective for lower values of elastic moduli and lower values of Richardson number, but this is not significant. As compared to other studies with flexible wall, it was observed that the location of the flexible part is important for the amount heat transfer enhancement with flexible wall. However, including single walled carbon nanotubes to the water results in significant heat transfer enhancements due to the very higher thermal conductivities of carbon nanotubes. Unsteady effects, different thermal boundary conditions, size and location of the partial heater, location of the flexible wall and multiple-walled carbon nanotube effects will be considered in future studies.

\section{NOMENCLATURE}

$\begin{array}{ll}\mathrm{CNT} & \text { Carbon nanotube } \\ \mathrm{E} & \text { Elastic modulus } \\ \mathrm{g} & \text { Gravity acceleration } \\ \mathrm{Gr} & \text { Grashof number } \\ \mathrm{h} & \text { Partial heater size } \\ \mathrm{h} & \text { Heat transfer coefficient } \\ \mathrm{H} & \text { Length of enclosure } \\ \mathrm{Nu} & \text { Nusselt number } \\ \mathrm{Re} & \text { Reynolds number } \\ \mathrm{Ri} & \text { Richardson number } \\ \mathrm{SWCNT} & \text { Single walled carbon nanotube } \\ \mathrm{T} & \text { Temperature } \\ \mathrm{u}, \mathrm{v} & \text { Velocity components } \\ \mathrm{u} & \text { Tangential velocity of inclined wall } \\ \mathrm{x}, \mathrm{y} & \text { Cartesian coordinates } \\ \alpha & \text { Thermal diffusivity } \\ \beta & \text { Thermal expansion coefficient }\end{array}$


Journal of Thermal Engineering, Research Article, Vol. 6, No. 6, Special Issue 12, pp. 379-387, December, 2020

$\varphi \quad$ Solid nanoparticle volume fraction

$\Theta \quad$ Non-dimensional temperature

\section{REFERENCES}

[1] Khanafer K, Vafai K, Gaith, M. Fluid-structure interaction analysis of flow and heat transfer characteristics around a flexible microcantilever in a fluidic cell. International Communications in Heat and Mass Transfer. 2016; 75:315-22.

[2] Jamesahar E, Ghalambaz M, Chamkha AJ. Fluid-solid interaction in natural convection heat transfer in a square cavity with a perfectly thermal conductive flexible diagonal partition. International Journal of Heat and Mass Transfer. 2016; 100:303-19.

[3] Selimefendigil F, Oztop HF, Abu-Hamdeh N. Mixed convection due to rotating cylinder in an internally heated and flexible walled cavity filled with $\mathrm{SiO}_{2}$-water nanofluids: Effect of nanoparticle shape. International Communications in Heat and Mass Transfer. 2016; 71:168-78.

[4] Khanafer K. Comparison of flow and heat transfer characteristics in a lid-driven cavity between flexible and modified geometry of a heated bottom wall. International Journal of Heat and Mass Transfer. 2014; 78:1032-41.

[5] Oztop HF, Abu-Nada E. Numerical study of natural convection in partially heated rectangular enclosures filled with nanofluids. International Journal of Heat and Fluid Flow. 2008; 29: 1326-36.

[6] Lazarus G. Nanofluid heat transfer and applications, Journal of Thermal Engineering. 2015; 1(2):113-15.

[7] Ravisankar R. Application of nanotechnology to improve the performance of tractor radiator using cu-water nanofluid. Journal of Thermal Engineering. 2018; 4(4):2188-2200.

[8] Imtiaz M, Hayat T, Alsaedi A, Ahmad B. Convective flow of carbon nanotubes between rotating stretchable disks with thermal radiation effects. International Journal of Heat and Mass Transfer. 2016; 101:948-57.

[9] Yazid MNAM, Sidika NAC, Yahya WJ. Heat and mass transfer characteristics of carbon nanotube nanofluids: A review. Renewable and Sustainable Energy Reviews. 2017; 80:914-41.

[10] Kamali R, Binesh A. Numerical investigation of heat transfer enhancement using carbon nanotube-based non-Newtonian nanofluids. International Communications in Heat and Mass Transfer. 2010; 37:1153-57.

[11] Estellé P, Halelfadl S, Maré T . Thermal conductivity of CNT water based nanofluids: Experimental trends and models overview. Journal of Thermal Engineering. 2015; 1(2):381-390.

[12] Brinkman H. The viscosity of concentrated suspensions and solutions. Journal of Chemical Physics. 1952; 20:571.

[13] Reddy JN, Gartling DK. The finite element method in heat transfer and fluid dynamics. Boca Raton, Florida: CRC Press; 1994.

[14] Lewis RW, Nithiarasu P, Seetharamu KN. Fundamentals of the finite element method for heat and fluid flow. John Wiley \& Son; 2004.

[15] Selimefendigil F, Öztop HF, Chamkha AJ. Analysis of mixed convection of nanofluid in a 3D lid-driven trapezoidal cavity with flexible side surfaces and inner cylinder. International Communications in Heat and Mass Transfer. 2017; 87:40-51.

[16] Selimefendigil F, Öztop HF. Natural convection in a flexible sided triangular cavity with internal heat generation under the effect of inclined magnetic field. Journal of Magnetism and Magnetic Materials. 2016; 417:327-37. 